\title{
El legado familiar: Una aproximación a las tacanot hispánicas relativas al matrimonio y la devolución patrimonial (siglos XIII-XV)*
}

\author{
Marina Girona Berenguer ${ }^{* *}$ \\ ILC, CSIC
}

ORCID ID: https://orcid.org/0000-0003-4885-6847

Este artículo presenta el estudio de varias tacanot $\mathrm{u}$ ordenanzas comunitarias judías destinadas a regular la práctica matrimonial y la devolución del patrimonio. Dichas leyes fueron promulgadas por diferentes comunidades de judíos de origen hispánico entre los siglos XIII y xV, y ponen de manifiesto la necesidad e importancia de legislar sobre aspectos concernientes a la unidad social básica: la familia. A través del análisis individualizado y conjunto de las ordenanzas, se establecen dos modelos de devolución patrimonial derivados de dos regímenes matrimoniales distintos: el de bienes comunes y el de capitulación o separación de bienes.

PALABRAS ClAVE: Matrimonio; herencia; patrimonio familiar; ordenanzas; leyes locales; costumbres legales.

The Familial Legacy: An Approach to the Hispano-Jewish TakKanot on Marriage and Devolution (Thirteenth-Fifteenth Centuries).- This paper studies several takkanot or local ordinances regarding marital practices and devolution of marriage assets, issued by different Hispano-Jewish communities between the thirteenth and the fifteenth centuries. These takkanot reveal the need and importance of regulating legal customs related to the basic social unity: the family. Throughout an individual and combined analysis of the ordinances, two models of devolution are established depending on whether the married couple had arranged a separate or common property system.

* Este estudio ha sido realizado en el marco de los proyectos de investigación «Guinzé Sefarad (2013-2015): Edición y estudio de documentos históricos y textos halájicos hebreos y aljamiados» [HAR2012-34338] y «The Jews in the European Mediterranean Societies. A Long-Term Perspective: Fourteenth to Nineteenth Century (JEuMed)» [PIC2017FR2]. Quisiera agradecer a los profesores Javier Castaño (CSIC) y Asunción Blasco Martínez (Universidad de Zaragoza) los comentarios y sugerencias vertidos a medida que se gestaba este trabajo.

** marina.girona@cchs.csic.es

Copyright: (C) 2021 CSIC. Este es un artículo de acceso abierto distribuido bajo los términos de la licencia de uso y distribución Creative Commons Reconocimiento 4.0 Internacional (CC BY 4.0). 
KeYwords: Marriage; Inheritance; Familial Estate; Takkanot; Local Jewish Law; Minhagim.

En época medieval, las contribuciones económicas realizadas por dos familias judías con objeto de formalizar el casamiento de dos de sus miembros requerían una garantía de restitución. Es por esto que algunos contratos matrimoniales (ketubot) contienen cláusulas que especifican cómo se debía proceder a la devolución de dichos bienes tras la ruptura natural del matrimonio, según el acuerdo alcanzado por las familias de los futuros contrayentes ${ }^{1}$. La importancia de este asunto trasciende el ámbito familiar y se verifica, igualmente, en la correspondencia jurídica entre las autoridades rabínicas y, en particular, en la legislación emitida por las aljamas hispánicas a lo largo del Medievo en forma de acuerdos (hascamot) y ordenanzas (tacanot).

Las hascamot eran los acuerdos legales alcanzados por los dirigentes de una aljama, que solían derivar en la promulgación de tacanot u ordenanzas comunitarias. Estas normas emanaban de unas necesidades comunitarias específicas que precisaban el establecimiento de unos estatutos legales de duración limitada ${ }^{2}$. Así, hascamot y tacanot se presentan como el resultado de la adaptación de la ley judía a los nuevos tiempos y regulan diferentes aspectos de la sociedad judía medieval (estructura comunitaria, transgresiones y penas, leyes suntuarias, etc.), tratando de hacer compatible la vida interna de las comunidades con la del reino en cuestión ${ }^{3}$.

1 Así se observa en las ketubot de rabí Simuel Azafar y Buena Alcastiel (Tudela, 1480), y de rabí Natán de Narbona y Dueña Alsebilí (Borja, 1482); vid. José Luis LaCAVE, Navarra Judaica. Los judios del Reino de Navarra. Documentos hebreos 1297-1486, vol. VII [en adelante, Navarra Judaica VII] (Pamplona: Gobierno de Navarra. Departamento de Educación y Cultura, 1998) págs. 449-451 (doc. 58) y 466 (doc. 59).

2 «Un monde aux dimensions limitées, mais d'une extraordinaire activité pour ce qui est de la production de lois, c'est-à-dire d'un code de comportement spécifique»; $c f$. Giacomo Todeschins, «Familles juives et chrétiennes en Italie à la fin du Moyen Age: deux modèles de développement économique», Annales. Histoire, Sciences Sociales 4 (1990) págs. 787-817: 789 .

3 Pese a que algún autor ha considerado que en los reinos hispánicos no existieron tentativas de uniformar los ordenamientos de las comunidades hasta mediados del siglo XIV (vid. Louis FinkelsteIn, Jewish Self-Government in the Middle Ages [New York: 
Partiendo de la base de que las sociedades judías medievales contemplan la idea de que todo individuo que alcanza la madurez está destinado a desposarse, resulta lógico que los rabinos y las élites comunitarias dedicaran una atención especial a cuestiones que podían ocasionar disputas en el seno familiar, tales como los acuerdos conducentes a un casamiento y su celebración, la distribución de la herencia y el pago de las deudas dejadas por una persona fallecida.

Este artículo examina las leyes destinadas a regular las prácticas matrimoniales y de devolución patrimonial entre los judíos de los reinos hispánicos durante el período pleno y bajomedieval. En primer lugar, se abordará la relación entre la práctica matrimonial y la devolución patrimonial, así como las características principales de los modelos de devolución, destacando algunos debates jurídicos surgidos al respecto. Dada la tradición de este tipo de normativa entre las comunidades hispanojudías, a continuación, se presentará el análisis de varias ordenanzas comunitarias promulgadas entre los siglos XIII y XV. Estas disposiciones brindan el marco jurídico-legal local en materia de devolución que tenían que seguir los judíos en dicho lugar, sin desatender las normas promulgadas previamente.

\section{LA DEVOlución de LOS BIENES MATRIMONIALES: UN ASUNTO DE ESPECIAL INTERÉS PARA LA COMUNIDAD JUDÍA MEDIEVAL}

El estudio de los modelos de devolución patrimonial despierta un creciente interés por parte de los investigadores dedicados a la historia de los judíos ${ }^{4}$. Por ello, antes de entrar en materia, es conveniente trazar algunas premisas introductorias relativas al sistema de devolución entre los judíos durante la Plena y Baja Edad Media:

Philipp Feldheim, 1924] págs. 100-101), no se debería minusvalorar el impulso de las aljamas en la promulgación de ordenanzas a nivel local.

${ }^{4}$ Michaël Gasperoni (CNRS), Pierre Savy (EFR) y Javier Castaño (CSIC) organizaron sendos seminarios en París (2016), Roma (2017) y Madrid (2018) respectivamente, destinados a esclarecer los modelos de devolución empleados por los judíos en el espacio mediterráneo-europeo occidental durante los períodos bajomedieval y alto-moderno. Los resultados de estos encuentros se publicarán en el volumen A Jewish Model of Devolution? The Inheritance in the Medieval and Modern Jewish Societies (Brill). 
a) Partiendo de la normativa de sucesión establecida en la Torá ${ }^{5}$, en la Edad Media se genera toda una pluralidad de modelos de devolución de carácter particular -los establecidos por las familias en las capitulaciones matrimoniales- y comunitario o local -los estipulados por las aljamas.

b) Existe un modelo relativo a la transmisión de los bienes de la ketubá, es decir la dote (nedunyá) y las arras (toséfet), que excluye al cónyuge superviviente de la herencia del fallecido (modelo 1, lo que se conoce como modelo de capitulación o separación de bienes).

c) También se constata otro modelo destinado a regular la devolución de la herencia de cualquier cónyuge (modelo 2, lo que se conoce como modelo de bienes comunes).

d) Si una persona viuda o divorciada fallecía $a b$ intestato y sin descendientes (zera '̌́el cayamá), sus parientes se convertían en herederos (yoršim) y recibían la herencia, dando prioridad al padre.

e) Si una persona viuda o divorciada fallecía ab intestato y con hijos, la herencia era distribuida entre sus descendientes, dando prioridad a las hijas casaderas y excluyendo, por lo general, a las casadas.

El interés en regular la devolución de la herencia (en especial, de los bienes matrimoniales) no solo se observa en la configuración de un amplio corpus jurídico, sino que con ello se intentaba poner fin a una problemática situada en el epicentro de los litigios: los pleitos por herencia y por dote y $\operatorname{arras}^{6}$. Aunque los judíos de los reinos hispánicos no estaban obligados a

$5 N u$ 27,8-11. La herencia del padre debe ser transmitida a sus hijos varones; ante la ausencia de estos, la recibirían las hijas. Si no hubiera descendientes, los herederos serían los hermanos del fallecido, y, en caso de que tampoco hubiera, los destinatarios serían otros parientes del fallecido.

${ }^{6}$ Elka Klein ya apuntó la necesidad de emprender una investigación sobre la legislación comunitaria en materia de sucesión, a fin de contextualizar, de una manera más adecuada, los conflictos por herencia surgidos en el seno de la judería hispano-medieval; vid. Elka KLEIN, «Protecting the Widow and the Orphan. A Case Study from $13^{\text {th }}$ Century Barcelona», Mosaic 14 (1993) págs. 65-81; «The Widow's Portion: Law, Custom, and Marital Property among Medieval Catalan Jews», Viator 31 (2000) págs. 147-163, y «Splitting heirs: Patterns of Inheritance among Barcelona's Jews», Jewish History 16 (2002) págs. 49-71. En particular, los fondos documentales del Registro General del Sello (Archivo General Simancas) y del Registro de Ejecutorias (Archivo de la Real Chancillería de Valladolid) revelan esta realidad para la Castilla del siglo xv; vid. Marina 
transmitir sus bienes únicamente a sus herederos legítimos (o parientes), era recomendable que respetaran las leyes de sucesión establecidas por la comunidad para no perjudicar económicamente a su familia.

El proceso de devolución tenía en cuenta un orden de prelación legal: primero, se encontraban las capitulaciones matrimoniales, consecuencia de las reuniones y negociaciones inter-familiares llevadas a cabo antes de la celebración del casamiento o con posterioridad al mismo. En segundo lugar, las tacanot $\mathrm{u}$ ordenanzas, que regulaban la transmisión de los bienes matrimoniales y/o en régimen de bienes comunes. Ante la ausencia de ordenanzas, el modelo de devolución se inspiraba en la costumbre local (minhag) ${ }^{7}$, que derivaba de la existencia de una ordenanza previa ${ }^{8}$.

\subsection{En torno a la transmisión de los bienes de la ketubá}

En las negociaciones previas a un casamiento, las familias de los cónyuges podían determinar el modelo de devolución de los bienes de la ketubá. En este sentido, la promulgación de tacanot relativas a la devolución de la dote y las arras fijaba un modelo con el que se pretendía, además, resolver los casos de fallecimiento ab intestato o compensar la ausencia de capitulaciones matrimoniales. El principal propósito de estas leyes, que se constatan a lo largo del tiempo y en diferentes regiones ${ }^{9}$, era evitar la oposición del marido a devolver a la familia de

Girona Berenguer, Mujeres judias, devolución de la dote y transmisión de la herencia (Castilla, siglo XV) (Tesis doctoral. Madrid: Universidad Complutense de Madrid, 2020).

7 En materia halájica, tradicionalmente se ha considerado que las aljamas de judíos en territorio hispánico se guiaron fundamentalmente por el código de Maimónides; $c f$. José Luis LACAVE, «Las leyes matrimoniales en las taqqanot españolas», en Rashi 10401990. Hommage à Ephraïm E. Urbach, ed. Gabrielle Sed-RajnA (Paris: Cerf, 1993) págs. 677-682: 677. En las tacanot de Tudela (1305) se menciona explícitamente que «en esta ciudad no se emitirá veredicto en ningún juicio, trate de lo que trate, si no es siguiendo la opinión de nuestro maestro Moisés (Maimónides), de bendita memoria»; cf. Navarra Judaica VII, pág. 30 (doc. 1).

8 Vid. Marina Girona Berenguer, «Vestigios de la costumbre local relativa al régimen matrimonial entre los judíos de Castilla (Salamanca, 1500)», Sefarad 78 (2018) págs. 35-62.

9 Por ejemplo, en el siglo XvIII, la comunidad judía de Roma estableció que, si el marido falleciera con o sin hijos, a la viuda se le debería entregar su dote, las arras y 
la mujer los bienes aportados al matrimonio o, en su defecto, la negativa de la familia del varón a restituir la dote a la viuda.

Circunstancias como el fallecimiento de uno de los contrayentes antes de la boda o la disolución de un matrimonio sin descendencia a causa del fallecimiento de uno de los cónyuges podían generar controversia. Paradigma de ello fue la disputa jurídica sostenida por algunos rabinos asquenazíes durante los siglos XII-XIII en torno a la devolución de los bienes de la ketubá durante el primer y segundo año de matrimonio, tomando como base la tradición talmúdica.

El Talmud de Babilonia estipula que la familia de la novia no estaría obligada a entregar la dote si ella falleciera antes de la boda, aunque se hubiera puesto por escrito de forma contractual. Sin embargo, si la boda se hubiera celebrado, la familia perdería sus derechos sobre los bienes dotales ${ }^{10}$. A este respecto y con el propósito de amparar a la familia de la prometida, Rabbenu Tam (s. XII) rebatió la disposición talmúdica y dictaminó que el marido estaría obligado a devolver el importe íntegro de la dote a la familia de su mujer, si esta falleciera durante el primer año de matrimonio ${ }^{11}$. Este sabio justificó su ordenanza argumentando que un padre que había hecho el esfuerzo de dotar con abundancia a una hija, no debería perder dichos bienes si esta fallecía prematuramente ${ }^{12}$.

La reacción de las autoridades rabínicas de Centroeuropa al respecto fue dispar. Varias comunidades situadas al oeste del Rin aceptaron la

un quinto de las donaciones hechas por el marido a su mujer durante el matrimonio; si falleciera ella sin descendientes, su familia solo recuperaría un tercio de la dote. Respecto a esto último, las comunidades de Pésaro, Urbino y Senigallia (región de Las Marcas) acordaron que la familia de la mujer recuperaría la mitad de la dote; $c f$. Michaël GASPERONI, «La misura della dote. Alcune reflesioni sulla storia della famiglia ebraica nello Stato della Chiesa in età moderna», en Vicino al focolare e oltre. Spazi pubblici e privati, fisici e virtuali della donna ebrea in Italia (secc. XV-XX), ed. Laura GraZIANI SECCHIERI (Firenze: La Giuntina, 2015) págs. 175-216: 183.

10 bKetubot $47 \mathrm{a}$.

${ }^{11}$ Finkelstein, Jewish Self-Government in the Middle Ages, págs.160-168. Esta medida se inspiraba en el Talmud de Jerusalén, y era seguida por las comunidades de Provenza, según se señala en Avraham Grossman, Pious and Rebellious: Jewish Women in Medieval Europe (Waltham, Massachusetts: Brandeis University Press, 2004) pág. 110.

12 Aharon Shweka, «The Controversy about the Marriage Statute (Taqqanot haNissu'in) of Toledo» [heb.], Tarbiz 68 (1998) págs. 87-127: 90. 
norma haciéndola extensible hasta el segundo año de matrimonio ${ }^{13}$. Además, otorgaron a la familia del marido el derecho a recuperar la mitad de las arras en caso de que este falleciera durante el mismo período. Otras comunidades optaron por respetar la disposición babilónica que solo contempla que la devolución se realizara antes de la boda ${ }^{14}$.

A falta de un estudio que determine si en los textos halájicos de procedencia hispánica se documentan atisbos de esta problemática, cabe decir que en las consultas hechas a expertos en ley judía, la transmisión de los bienes del matrimonio ocupa un lugar destacado desde, al menos, el siglo XIII ${ }^{15}$. Conocer cuál era el modelo de devolución por el que se regía una aljama o cómo se debía resolver un problema de sucesión matrimonial eran algunas de las cuestiones dirigidas a los expertos halájicos. Buen ejemplo de ello es el responsum enviado por R. Isaac Perfet a Hayyim bar Yosef ha-Leví a propósito de la herencia de Sol, esposa de Israel ben Israel, judíos de Daroca ${ }^{16}$. En el supuesto casuístico se contiene que, si Dina (personaje ficticio) enfermara y quisiera disponer sus últimas voluntades, solo tendría derecho a hacer mandas de hasta un tercio del importe de su dote (4.000 sueldos), puesto que, en caso de fallecer sin descendientes, los dos tercios restantes quedarían para el marido. A través del texto se define el modelo que regía la devolución de los bienes de la ketubá en Aragón

13 Shalem Yahalom, «The Dowry Return Edict of R. Tam in Medieval Europe», European Journal of Jewish Studies 12 (2018) págs. 136-167: 144.

${ }^{14}$ La oposición más firme a la ordenanza de Rabbenu Tam es la de R. Eliezer de Touques (s. XIII), uno de los autores de Tosafot; $c f$. YAHALOM, «The Dowry Return Edict of R. Tam in Medieval Europe», págs. 146-149.

15 R. Šelomó ben Adret recogió el testigo de varias ordenanzas promulgadas por diferentes aljamas castellanas (s. XIII) para establecer la devolución de los bienes de la ketubá en caso de fallecimiento sin descendencia; vid. R. Šelomó ben Adret, Colección de responsa, I:1125; III:432; V:228. Las referencias a los responsa contenidos en el presente trabajo han sido tomadas de la edición del Bar-Ilan Responsa Project (versión año 2007).

16 Se trata de un texto original en aljamía hebraico-romance, en el que se recoge: «Y porque trobo que de ley de judíos es que si la muller muere antes que el marido, finca heredero de la forma o formas de $\operatorname{ar}[\mathrm{r}]$ as de la muller, por esto quiero e mando que si contesiera por ventura que la dita dona Sol morise ante que el dito rabí Israel, marido suyo, que ella pueda ordonar [sic] ansí de su muerte en contía de 4 mil sueldos a qui ella quiera, de los 10 mil sueldos que le mandé firmar por ar[r]as e en manera de ar[r]as, e non más»; vid. R. Isaac ben Perfet, Colección de responsa, responsum 207. 
a mediados del siglo xIv; esto es, si la mujer falleciera sin descendientes, el marido recibiría dos tercios de la dote y los herederos el tercio restante.

\subsection{El modelo de devolución del patrimonio}

A diferencia de la ordenanza de Rabbenu Tam, fruto de un modelo de capitulación o separación de bienes (modelo 1), otras ordenanzas tienen por objeto regular la transmisión patrimonial en un régimen de bienes comunes o si, además, hubiera descendientes y la viuda renunciara a los bienes de la ketubá (modelo 2).

De acuerdo con el modelo de capitulación, la mujer debería recibir su dote ante un tribunal, si bien, antes debería recibir el beneplácito de los herederos ${ }^{17}$. Por lo general, los encargados de la restitución serían los receptores de la herencia. No obstante, la documentación histórica constata el compromiso de otros familiares como garantes ('arebim) de las arras y donaciones hechas por el marido en el momento de la formalización de la ketubá. Ante la ausencia de descendientes o si estos fueran menores de edad, serían los garantes, los que estarían obligados a devolver los bienes a la viuda.

Si un matrimonio hubiera establecido un régimen de bienes propios, tras el fallecimiento del marido, la viuda no sería considerada heredera y solo tendría derecho a recuperar su dote. Sin embargo, podría renunciar a sus derechos sobre los bienes de la ketubá con el fin de tomar parte de la herencia, siempre y cuando recibiera el beneplácito de los herederos. De este modo, los bienes de la ketubá pasarían a engrosar el «montón»o fondo común de la herencia del fallecido, si bien la viuda, al ser considerada una heredera más, no podría recuperar el importe de la dote aportada por su familia originariamente.

Por el contrario, ante el fallecimiento de la mujer no solía contemplarse el uso de este primer modelo (que obligaba al marido a devolver la totalidad de la dote a la familia de esta), salvo que existiera una ordenanza explícita al respecto como fue la de Rabbenu Tam, lo que significa que, por lo general, el marido sí solía heredar de su mujer ${ }^{18}$.

17 Maimónides, Hiljot Išut, 16:11.

18 Tanto de los bienes del contrato, como de los parafernales y el dinero. 
La herencia (o parte de ella, dependiendo del modelo ${ }^{19}$ ), compuesta por los bienes muebles, inmuebles y el dinero (roš mamón), sería para los descendientes o los herederos. En el momento en el que hubiera hijos, los parientes o herederos quedarían excluidos del proceso de devolución, si el cónyuge fallecido no hubiera hecho alguna manda particular. En este sentido, la existencia de esta garantía post-talmúdica otorgaba a los hijos el derecho a heredar la ketubá de su madre (o parte de la misma) y evitaba que el marido fuera el único beneficiario.

Asimismo, algunas leyes disponen que, si una persona casada falleciera sin hijos, su padre o hermanos varones serían considerados jurídicamente descendientes. La norma talmúdica señala que el padre hereda de cualquier hijo ${ }^{20}$ (en especial, si falleciera antes de contraer matrimonio). Otras disposiciones también contemplan que la madre herede de sus vástagos ${ }^{21}$ (por ejemplo, si hubiera contribuido en la dotación de su hija ${ }^{22}$ ).

\subsection{Las deudas del cónyuge fallecido}

En las ordenanzas destinadas a regular cuestiones de herencia se hallan referencias al pago de las deudas contraídas por cónyuge fallecido $^{23}$. Este hecho pone de manifiesto el compromiso que adquirían los herederos y descendientes al recibir una porción de la herencia, puesto

${ }_{19}$ El marido recibiría el total de la herencia de la mujer en el primer modelo de devolución, mientras que, en caso de régimen de bienes comunes, dicho patrimonio sería dividido entre el cónyuge superviviente y los herederos/descendientes.

${ }^{20}$ bBaba Batra 108a. Es por esta razón que no se considera necesario establecer cómo sería la distribución de la herencia de un individuo que falleciera menor de edad o soltero (siempre y cuando no hubiera hecho testamento).

${ }^{21}$ Pese a que la ley talmúdica estipula que una madre no hereda de su hijo varón; vid. MAIMÓNIDES, Hiljot Nahalot, 1:2.

22 Así se establece en una de las tacanot de Toledo (s. XIII); cf. Shraga Abramson, «On the Takkanah of Tuletula (Toledo) regarding the Husband's Inheritance of his Wife's Estate» [heb.], Zion 60 (1995) págs. 201-224: 224.

${ }^{23}$ Es remarcable que en las ordenanzas se incluya a la mujer como deudora, ya que, durante el matrimonio, no tenía potestad para contraer deudas, salvo que el marido le concediera permiso. 
que desde el momento que la aceptaban, quedaban obligados a asumir las deudas del cónyuge difunto.

Por lo general, la viuda que decidiera recuperar su ketubá, quedaría exenta de abonar las deudas de su marido, al igual que ocurría si el matrimonio no tuviera descendientes. Sin embargo, si hubiera hijos y la mujer renunciara a su contrato, esta sí debería contribuir en el pago de los débitos junto a los descendientes.

No obstante, un individuo que disponía sus últimas voluntades podía designar en ellas albaceas encargados de realizar el pago de las deudas de los bienes de la herencia, eximiendo a la viuda y a los hijos de realizar dicha tarea; sobre todo, cuando se trataba de huérfanos menores de edad. En el momento de formalizar el contrato por nupcias, el novio también podría ofrecer garantes que abonaran las deudas, incluso de sus propios bienes si se careciera de medios suficientes. En la praxis, esta medida solía generar problemas cuando los acreedores reclamaban el reembolso de las deudas y los garantes eludían sus obligaciones.

\section{ECOS DE LA TRADICIÓN HISPÁNICA EN MATERIA DE DEVOLUCIÓN}

Durante la Plena y Baja Edad Media, las aljamas de judíos de los territorios de las Coronas de Castilla y Aragón y del reino de Navarra promulgaron ordenanzas y estatutos, basados en acuerdos comunitarios, que sirvieron de marco legal para las costumbres locales ${ }^{24}$. Estas leyes, cuya máxima pretensión era regular asuntos internos de la comunidad, solían tener carácter local y una duración restringida.

A través de los textos de las tacanot, así como de los responsa rabínicos, hay constancia de que, desde finales del siglo XIII hasta la última

${ }^{24}$ Ejemplo de ello son las tacanot locales promulgadas por la aljama de Tudela (1287-1305); vid. Fritz BaER, Die Juden im christlichen Spanien. I. Urkunden und Regesten. 1. Aragonien und Navarra (Berlin: Akademie Verlag, 1929) págs. 948-957 (doc. 586), y Navarra Judaica VII, págs. 24-43 (doc. 1); y las ordenanzas generales acordadas por las aljamas de Castilla en 1432; vid. BAER, Aragonien, págs. 280-298; Yolanda MoRENo Koch, De iure hispano-hebraico. Las Taqqanot de Valladolid de 1432. Un estatuto comunal renovador (Salamanca: Universidad Pontificia de Salamanca, 1987), y Laura Minervini, Testi giudeo spagnoli medievali: Castiglia e Aragona (Napoli: Liguori Editore, 1992) vol. I, págs. 181-255 (doc. 16). 
década del siglo $\mathrm{xv}$, las comunidades judías hispánicas emitieron ordenanzas destinadas a legislar cuestiones concernientes al matrimonio y a la herencia ${ }^{25}$. El objeto de estas normas era establecer un modelo de devolución de los bienes de los cónyuges (modelo 1, de capitulación, y modelo 2, de bienes comunes), así como asegurar que los hijos recibieran la porción adecuada de la herencia de sus progenitores ${ }^{26}$.

Entre las ordenanzas locales promulgadas que conocemos en la Corona de Castilla ${ }^{27}$ destacan las tacanot de Toledo, Molina y Soria (siglo XIII), cuyo contenido se ha transmitido a través de varios responsa de R. Šelomó ben Adret, R. Ašer ben Yehiel y R. Isaac Perfet. Coetáneas a estas son las emitidas por la aljama de Tudela (1305), que han sido publicadas, primero, por Yitzhak Baer y luego, por José Luis Lacave, que también aportó una traducción al español ${ }^{28}$.

De igual modo, a lo largo del siglo xIV, otras aljamas (Valencia y Palma de Mallorca) emitieron normas de similar contenido, mencionadas en la correspondencia de R. Isaac Perfet y de R. Šimón ben Șémah Durán. En los responsa de este último sabio también se contienen las tacanot acordadas en 1394 por un grupo de judíos procedentes de la Corona de Aragón que se asentaron en Argel a consecuencia de las persecuciones de 1391.

Por último, las ordenanzas emitidas en 1494 y 1496 en la ciudad norteafricana de Fez por judíos originarios de Castilla evocan la tradición jurídica a la que se ha aludido. El hecho de que los expulsados

25 Para el período bajomedieval se conocen otras ordenanzas relativas a las prácticas matrimoniales: sendas tacanot promulgadas por las aljamas de Tortosa y Salamanca (s. XIV) regulaban la presencia de un minián en la ceremonia de una boda; vid. R. Isaac Perfet, Colección de responsa, responsa 232 y 399; $c f$. Abraham M. Hershman, Rabbi Isaac ben Sheshet Perfet and His Times (New York: The Jewish Theological Seminary of America, 1943) págs. 126 y 128. Posteriormente, también se acordaría así en las tacanot de Valladolid (1432), cap. 3, fol. 11.

26 Shweka, «The Controversy about The Marriage Statute (Taqqanot ha-Nissu'in) of Toledo», pág. 90.

${ }^{27}$ Referencias a otras leyes en materia de devolución promulgadas por comunidades castellanas se contienen en responsa de R. Yom Tob ben Abraham Išbilí y R. Yehudá ben Ašer; $c f$. ShwekA, «The Controversy about The Marriage Statute (Taqqanot haNissu'in) of Toledo», pág. 89 (notas 10 y 11).

${ }^{28}$ BAER, Aragonien, págs. 953-955 (doc. 586); Navarra Judaica VII, págs. 23-43 (doc. 1). 
decidieran legislar sobre el sistema de devolución, se debió a la necesidad de homogeneizar las costumbres previas y de dotar al conjunto de un entramado legal que lo constituyera en aljama. Las primeras tacanot de Fez son una fuente de notable valor para el estudio retrospectivo de la devolución en régimen de bienes comunes entre los judíos de Castilla a finales del siglo xv, al igual que lo son las ordenanzas de Argel (1394) para estudiar las costumbres previas entre los judíos de Aragón. Es por esta razón que se ha decidido incorporarlas en este estudio.

\section{OrdenANZAS PROMUlgadAS EN EL SIGLO XIII}

\subsection{Las tacanot de Toledo}

Las tacanot de Toledo se redactaron en judeo-árabe ${ }^{29}$, tenían una duración de 50 años e iban acompañadas de una pena de expulsión y excomunión (hérem y nidduy). Fueron promulgadas en el siglo XIII ${ }^{30}$ y se conocen, especialmente, por un responsum de R. Ašer ben Yehiel ${ }^{31}$.

${ }^{29}$ Las tacanot fueron centro del debate que R. Ašer ben Yehiel sostuvo con el escriba o sofer Israel ben Israelí, de Toledo, acerca de la interpretación que aquel hizo sobre el texto de las ordenanzas. R. Ašer ben Yehiel había solicitado una traducción al hebreo de dichas leyes con motivo de una consulta relacionada con el modelo de devolución establecido por la aljama. La polémica surgió respecto a la capacidad jurídica de la mujer para hacer una donación de la parte correspondiente a los herederos; $c f$. Jacob Leib TeIcHER, «Laws of Reason and Laws of Religions: a Conflict in Toledo Jewry in the Fourteenth Century», en Essays and Studies presented to Stanley A. Cook in Celebration of his Seventy-Fifth Birthday, ed. D. Winton Thomas (London: Taylor's Foreign Press, 1950) págs. 83-94, y Eleazar GutwirTH, «Asher B. Yehiel e Israel Israelí: actitudes hispano-judías hacia el árabe», en Creencias y culturas, coords. Alisa MeyuHas GinIo y Carlos CARrete PArrondo (Salamanca: Universidad Pontificia de Salamanca, 1998) págs. 97-111.

30 Teicher («Laws of Reason and Laws of Religions», pág. 84, nota 2), siguiendo a Simhá Assaf, considera que las tacanot fueron promulgadas en la primera mitad del siglo XIII. Como término ante quem se sabe que dichas leyes ya se habían promulgado cuando Jacob b. Šošán, miembro de una de las familias más prominentes de la ciudad, se erigió líder de la comunidad y fue nombrado «Rab» a mediados del siglo XIII.

${ }^{31}$ R. Ašer ben Yehiel, Colección de responsa, responsum 55, 5, 7 y 9. Otras referencias a las mismas se pueden leer en el tratado Eben ha-'Ezer de R. Jacob ben Ašer (118) y en un reponsum de Perfet (núm. 208), lo que confirma la importancia de estas leyes y su vigencia a lo largo de décadas; $c f$. Hershman, Rabbi Isaac ben Sheshet Perfet and His Times, págs.44-45 y 127-128. 
Posteriormente fueron estudiadas por Shraga Abramson ${ }^{32}$ y Aharón Shweka ${ }^{33}$, con un enfoque filológico. El primer estudio jurídico realizado en España sobre las mismas se debe al biblista y hebraísta José Llamas ${ }^{34}$, que aportó una traducción parcial de las mismas.

\subsubsection{Ruptura del matrimonio}

Aunque su contenido está destinado a establecer un modelo de devolución, en las ordenanzas también se legisla sobre el divorcio, puesto que la ruptura del matrimonio conllevaba una distribución específica de los bienes. Así, se establece que, si el marido solicitara el divorcio, la mujer tendría derecho a recuperar todos los bienes contenidos en la ketubá (la dote y las arras). Sin embargo, si fuera ella la que lo pidiera, solo tendría derecho a recuperar su dote, en caso de que el divorcio le fuera concedido. Si el marido entregara la carta de divorcio (guet) a su mujer en el lecho de muerte con el fin de liberarla de la ley del levirato, a la mujer se la consideraría viuda y no divorciada ${ }^{35}$, medida que también incluyen las tacanot de Fez (1494) ${ }^{36}$.

\subsubsection{Modelo de devolución}

En relación a la devolución, las tacanot de Toledo estipulan que el marido y los herederos de una mujer que falleciera sin hijos deberían dividir la dote en dos porciones iguales ${ }^{37}$. Esta acción repercutía ne-

32 Abramson, «On the Takkanah of Tuletula (Toledo) regarding the Husband's Inheritance of his Wife's Estate», págs. 201-224.

33 ShweKa, «The Controversy about The Marriage Statute (Taqqanot ha-Nissu'in) of Toledo», págs. 87-127.

34 José Llamas, «Documentos para la historia jurídica de las aljamas hebreas de Toledo y Molina», Religión y cultura 19 (1932) págs. 263-276.

35 También aparece recogido en el Šulhán Aruj de R. Yosef Caro (Eben ha-'Ezer, simán 118).

36 Tacanot de Fez (1494), núm. 14.

37 Llamas, «Documentos para la historia jurídica de las aljamas hebreas de Toledo y Molina», pág. 264, y Teicher, «Laws of Reason and Laws of Religions», pág. 84. 
gativamente en la familia de la fallecida que quedaba impedida para recuperar unos bienes que, en origen, le habían pertenecido. Si la mujer falleciera y su madre todavía estuviera viva, esta última tendría derecho a recuperar una parte de los bienes, vestidos y dinero que hubiera entregado para la dote de su hija, según se indicara en la ketubá. De este modo, la madre recibiría la mitad de dichos bienes y el viudo la otra porción, si bien este quedaría como receptor de la herencia de la fallecida.

De acuerdo con el responsum de R. Ašer ben Yehiel, el marido sí estaría obligado a repartir la herencia de su mujer con los descendientes de más de 30 días (independientemente de su sexo). Los hijos y las hijas casaderas tendrían derecho a heredar de sus progenitores, excluyendo a las hijas casadas ${ }^{38}$. Si el descendiente muriera siendo menor de edad y sin haberse desposado, la tradición bíblica especifica que el padre recibiría su parte de la herencia.

En caso de que el fallecido fuera el marido y el matrimonio no hubiera tenido descendencia, la viuda recuperaría su dote y recibiría un cuarto de la herencia de su marido (a modo de gracia especial), quedando el resto del patrimonio destinado para los herederos. Si, por el contrario, el matrimonio tuviera hijos, la viuda podría optar por recuperar los bienes de su ketubá o tomar parte de la herencia del marido, recibiendo una mitad.

\subsubsection{Pago de deudas}

Se ha hecho referencia anteriormente a la importancia de la transmisión de las deudas dejadas por los cónyuges tras su fallecimiento. En estas tacanot de Toledo se especifica que si la mujer falleciera dejando deudas pendientes de pago, primero se debería abonar los débitos pendientes y solo después se procedería al reparto de la herencia entre el marido y los herederos/descendientes ${ }^{39}$.

38 Esta práctica también se contiene en las tacanot de Fez (1494), núm. 8.

39 Llamas, «Documentos para la historia jurídica de las aljamas hebreas de Toledo y Molina», pág. 266. 


\subsection{Las tacanot de Molina}

Las ordenanzas de Molina fueron promulgadas en una fecha próxima a las tacanot de Toledo. Las disposiciones referentes a la devolución patrimonial se recogen en un responsum de R. Ašer ben Yehiel ${ }^{40}$.

En estas leyes se establece que, tras el fallecimiento del marido, la viuda debería custodiar la herencia de los huérfanos menores de edad. Una vez estos alcanzaran la madurez, podrían elegir entre devolver los bienes de la ketubá a su madre o dividir con ella la herencia del progenitor, como también se recoge en las leyes de Toledo.

En caso de que el marido falleciera sin descendientes, la viuda tendría derecho a recuperar su dote y recibiría la mitad de los bienes restantes de la ketubá. En esta ocasión, no recibiría de manera íntegra las arras, ni tampoco las donaciones que el marido le hubiera hecho ${ }^{41}$. Por lo tanto, a diferencia de lo decretado en Toledo, en Molina se excluía a la viuda de percibir otros bienes al margen de la ketubá.

\subsection{Las tacanot de Soria}

Una consulta jurídica dirigida a R. Šelomó ben Adret da a conocer la existencia de unas tacanot, de contenido similar, promulgadas por la aljama de Soria (s. XIII) ${ }^{42}$. La cuestión trataba de elucidar si los hijos de un primer matrimonio tendrían derecho a heredar de su madre, aunque esta se hubiera desposado por segunda vez.

En dichas ordenanzas se instituye que, si la mujer falleciera, el viudo y los hijos se repartirían la totalidad de sus bienes en dos mitades. En este sentido, R. Šelomó ben Adret solo consideraba herederos a los hijos

40 R. Ašer ben Yehiel, Colección de responsa, responsum 55, 7-8.

${ }^{41}$ Llamas, «Documentos para la historia jurídica de las aljamas hebreas de Toledo y Molina», págs. 266-267.

42 R. Šelomó ben Adret, Colección de responsa, III:432. Dadas las similitudes compartidas entre estas leyes y las ordenanzas de Toledo, algunos autores han asumido que la información contenida en este responsum hacía alusión a las últimas; $c f$. Isidore Epstern, The "Responsa" of Rabbi Solomon ben Adreth of Barcelona (1235-1310) (New York: Ktav Publishing House, 1925) págs. 85-86. 
que la mujer hubiera tenido en su último matrimonio. Por el contrario, ante la muerte del marido, todos los hijos que este hubiera tenido en matrimonio legal dividirían la herencia en dos mitades con la viuda, que no tendría derecho a reclamar su ketubá. Al igual que se observa en las tacanot de Toledo, las jóvenes casaderas recibirían una dote de la herencia de sus progenitores, anteponiéndose su dotación al reparto de la herencia entre el resto de descendientes.

En caso de que el matrimonio no concibiera descendencia, las ordenanzas de Soria establecen que la viuda recibiría su dote más un cuarto de la herencia del marido, y los herederos se quedarían con los tres cuartos restantes. Sin embargo, si falleciera la mujer, el viudo entregaría la mitad de la dote a los herederos y se convertiría en propietario del resto de bienes, una práctica idéntica a la acostumbrada entre los judíos de Toledo.

\section{OrdenanZas promulgadas en el Siglo XIV}

\subsection{Las tacanot de Tudela (1287-1305)}

A finales del siglo XIII y durante los primeros años del Trescientos, la aljama de Tudela promulga una serie de ordenanzas destinadas a regular diferentes aspectos de la vida comunitaria ${ }^{43}$. El texto de las tacanot de 1287 y 1305 se ha conservado en un cuadernillo de pergamino ${ }^{44}$ y su promulgación contaba con el respaldo de las familias más poderosas de la aljama ${ }^{45}$, cuyos miembros participaban en la asamblea de la comunidad y habían sido los encargados de ratificar su contenido. En

${ }^{43}$ BAER, Aragonien, págs. 948-957 (doc. 586), y Navarra Judaica VII, págs. 23-43 (doc. 1) y 45-49 (doc. 3).

44 «Acordó la aljama, guárdela su Roca y Redentor, asumir y confirmar todas las ordenanzas escritas y firmadas que constan en el cuadernillo de pergamino que está en poder de R. Moisés bar Yoel ben...; y todas las demás ordenanzas que no constan en el cuadernillo citado, invalidarlas y estimarlas como si nunca hubieran existido»; $c f$. $\mathrm{Na}$ varra Judaica VII, pág. 42 (doc. 1).

45 Falaquera, Abenabez, Evenpesat, Enxoeb, Evendeut, Evenminir, Camiç y Orabuena; cf. Navarra Judaica VII, pág. 42 (doc. 1). 
particular, las tacanot relativas al derecho de sucesión fueron validadas en 1305 , aunque se desconoce su período de vigencia.

\subsubsection{Modelo de devolución}

En primer lugar, se establece que, si el marido falleciera, los herederos/descendientes podrían elegir entre devolver a la viuda su dote o dividir con ella la herencia y, de esta manera, quedar liberados de las obligaciones de la ketubá. Si optaran por restituir la dote, la viuda se vería obligada a renunciar a todos los bienes restantes, salvo si el marido poseyera un patrimonio cuantioso; en ese caso, se le otorgaría la mitad del equivalente a su dote ${ }^{46}$.

La viuda que rehusara tomar su dote más la mitad de la misma o la mitad de la herencia con la intención de conservar otros bienes, sería multada con una pena de 1.000 maravedíes de oro. No obstante, esta normativa no sería aplicada con carácter retroactivo, ni tampoco prevalecería sobre las condiciones estipuladas entre los cónyuges, ya que los acuerdos particulares destinados a regular el matrimonio tenían mayor fuerza legal que las ordenanzas comunitarias, con la condición de que constaran por escrito con todas sus formalidades (fecha, lugar, firmas). Por lo tanto, si el matrimonio hubiera acordado la entrega de otros bienes específicos, esta estipulación primaría sobre lo establecido en la ordenanza.

$\mathrm{Si}$, por el contrario, la mujer falleciera dejando descendencia con derecho a heredar ${ }^{47}$, el marido debería entregar al heredero la mitad de la dote y él recibiría el resto de bienes (la mitad de la dote y la herencia). Si el padre prefiriera compartir la herencia con los hijos, podría hacerlo, siempre que no estuviera empleando una estrategia para limitar los derechos de los

${ }^{46}$ La restitución de la dote tras el fallecimiento del marido sin hijos sería un proceso de devolución equivalente al acostumbrado en las comunidades castellanas de Toledo, Molina y Soria, en las que la viuda siempre recibiría su dote más un añadido de mejora. Asimismo, en caso de que existieran descendientes se contempla la posibilidad de que estos dividieran con la viuda la herencia del fallecido.

47 Hijos mayores de tres años y medio o de cuatro años y medio; $c f$. Navarra Judaica VII, pág. 38 (doc. 1). 
descendientes, como se contempla en las leyes de Toledo. Asimismo, si falleciera uno de los descendientes, su porción sería repartida entre los demás; si se produjera el fallecimiento de todos los descendientes menores de doce años, el padre de la fallecida o sus descendientes (los hermanos de esta) recibirían una cuarta parte de la dote o de los bienes de la herencia.

Sin embargo, si no hubiera descendencia, el marido debería entregar al padre de la fallecida bien la mitad de la dote (al igual que se estipula en las ordenanzas de Toledo y Soria), bien la mitad de la herencia. En caso de que el padre hubiera fallecido, sus descendientes (es decir, los hermanos de la fallecida) recibirían la porción.

Según las disposiciones tudelanas, si una hija casadera no tuviera una dote, prevalecería sobre el resto de sus hermanos en la distribución de la herencia. Del mismo modo, si los adelantados de la aljama acordaran que la dote de una joven no era lo suficientemente abundante, se incrementaría por medio de los bienes dejados por el padre o la madre, y el resto sería para los varones ${ }^{48}$.

En cuanto a las hijas casadas, las ordenanzas de Tudela coinciden con las de Toledo al decretar que estas no tendrían derecho a heredar de sus progenitores, salvo que no hubiera hijos varones. En este caso, tanto las hijas solteras, como las casadas dividirían la herencia a partes iguales, una vez fueran dotadas las primeras.

\subsection{Costumbre legal en Valencia}

Los responsa de Perfet contienen referencias a otras costumbres y tacanot locales hispánicas relativas a la devolución patrimonial (siglo XIV) ${ }^{49}$.

${ }^{48}$ Como se puede observar, los bienes de la ketubá servían de trasvase para dotar a otra persona de la familia (ya fuera una hermana o una hija), lo que aseguraba el mantenimiento de dicho patrimonio en el seno familiar.

49 En la colección documental del mismo rabino se menciona la existencia de otras tacanot promulgadas por la aljama de judíos de Málaga, ciudad del reino nazarí a finales del XIV. En estas leyes se determina que, si el marido falleciera sin descendencia, la mujer tendría derecho a recuperar su dote y a recibir la mitad de la ketubá (arras); la otra mitad, la recibirían los herederos. Sin embargo, si la mujer hubiera ganado o adquirido otros bienes durante el matrimonio, incluso junto con su marido, dichas propiedades deberían ser restituidas íntegramente a su propietaria. Por otra parte, si la mujer falleciera sin hijos, los herederos no 
En un responsum fechado en 1402, Perfet explica que los judíos que habían vivido en Valencia (con anterioridad a 1391) observaban la costumbre o minhag, por la que el marido quedaba como el único heredero de los bienes de la ketubá tras fallecimiento de su mujer con descendientes ${ }^{50}$.

\subsection{Las tacanot de Palma de Mallorca}

En una respuesta de R. Šimón ben Șémah Durán se recoge que en Palma de Mallorca, ciudad en la que el rabino había vivido con su familia hasta 1391, existían unas ordenanzas que estipulaban que tras el fallecimiento de la mujer, los descendientes deberían recibir los bienes de la ketubá ${ }^{51}$. Ante la ausencia de hijos, el marido y los herederos se repartirían la dote en dos mitades, reservando al viudo el derecho a heredar el resto de propiedades de la fallecida, tal y como se acuerda en las ordenanzas de Toledo, Soria y Tudela.

\subsection{Las tacanot de Argel (1394)}

La llegada a Argel de judíos procedentes de diferentes territorios de la Corona de Aragón, a causa de los disturbios de 1391, propició la puesta a punto de un nuevo marco legal que unificara las costumbres legales de cada grupo y consolidara su establecimiento en dicho lugar. El punto de partida fue la creación en 1394 de unas ordenanzas en materia matrimonial y de devolución, en las que intervinieron R. Isaac Perfet, que había llegado desde Valencia, y R. Šimón ben Șémạ̣ Durán, procedente de Mallorca.

podrían reclamar la toséfet, sino que solamente recuperarían la dote (o parte de ella); $c f$. Isidore Epstein, The Responsa of Rabbi Shimon b. Zemah Duran, as a Source for the History of the Jews in North Africa (London: Oxford University Press, 1930) págs. 87-88, nota 41.

${ }^{50}$ R. Isaac Perfet, Colección de responsa, responsum 105. Esta es la única referencia en la que se reconoce al marido el derecho exclusivo a recibir los bienes de la ketubá en detrimento de los descendientes.

51 R. Šimón ben Șémah Durán, Colección de responsa, III:150; $c$. EpsteIn, The Responsa of Rabbi Shimon b. Zemah Duran, pág. 87, y Hershman, Rabbi Isaac ben Sheshet Perfet and His Times, pág. 45. 
Las tacanot se han conservado en un responsum de R. Šimón ben Șémah Durán, que había sido el encargado de elaborar su borrador ${ }^{52}$. Se trata de doce disposiciones junto a las que este autor añadió algunos comentarios exegéticos inspirados en las costumbres legales de tradición hispánica $(1420)^{53}$. Las ordenanzas fueron leídas un sábado en la sinagoga de Argel previo a la lectura de la perícopa semanal, y allí mismo fueron aceptadas por los asistentes. El documento fue ratificado con las firmas de los sabios de la aljama el 2 de elul de 5154, esto es el 30 de julio de $13944^{54}$.

\subsubsection{Práctica matrimonial}

Las dos primeras ordenanzas están destinadas a establecer la configuración de una ketubá. El contrato de una doncella virgen debería estar compuesto por el principal ('icar ketubá o móhar) (200 zuzim), la nedunyá y la toséfet, que equivaldría a la mitad de la dote aportada ${ }^{55}$. Sin embargo, en el caso de las viudas y las divorciadas, el novio no tendría que añadir dicha mejoría, tan solo el principal (100 zuzim), puesto que el estatus jurídico de la viuda (almaná) y la divorciada (meguréšet) era diferente al de la doncella (betulá), aunque siguieran siendo vírgenes ${ }^{56}$. El propósito de contribuir con la toséfet o adición era hacer más costoso (en términos económicos) el divorcio, ya que, si un matrimonio se hubiera disuelto por voluntad del marido, la mujer debería recibir la totalidad de su ketubá (incluida la toséfet). En contraposición a esto, si el divorcio fuera solicitado por la mujer y finalmente se le concediera, ella no tendría derecho sobre el incremento ${ }^{57}$.

52 R. Šimón ben Șémạ̣ Durán, Colección de responsa, II:292.

53 Epstein, The Responsa of Rabbi Shimon b. Zemah Duran, págs. 84-87.

54 Tacanot de Argel (1394), núm. 12.

${ }^{55}$ Esta regulación se diferencia de la ley talmúdica que establece la cantidad adicional o toséfet en un tercio de la dote; $c f$. Epstern, The Responsa of Rabbi Shimon $b$. Zemah Duran, pág. 85.

56 Tacanot de Argel (1394), núm. 1.

57 Tacanot de Argel (1394), núm. 2. 


\subsubsection{Modelo de devolución}

Las tacanot 3-7 contienen las disposiciones destinadas a la regulación de la devolución de la ketubá. Primero, se acuerda que, si la mujer falleciera dejando hijos de más de 30 días de edad, la nedunyá sería repartida en dos partes iguales entre el marido y los descendientes (hijos e hijas). Al tratarse de bienes inalienables (șon barzel), durante su vida, la propietaria no podría venderlos, ni empeñarlos, ni tampoco darlos en donación o últimas voluntades. En este caso, el principal de la ketubá y la toséfet también los heredaría el marido ${ }^{58}$. $\mathrm{Si}$, por el contrario, la mujer falleciera sin descendencia, el marido recibiría dos tercios de la dote, mientras que los parientes más próximos tomarían el tercio restante. Al igual que en las tacanot de Toledo, esta ordenanza dotaba a la mujer de capacidad jurídica para transferir el tercio destinado a los herederos al marido u otro pariente tras su fallecimiento, según fuera su voluntad ${ }^{59}$.

En caso de que el marido falleciera, la viuda solo recibiría el móhar y su nedunyá, y no podría reclamar la toséfet ${ }^{60}$. Respecto a la donación aparte (mataná le-hud), la viuda no la recibiría ni a causa de divorcio, ni por fallecimiento del cónyuge ${ }^{61}$. Esto es debido a que, en aquel tiempo, la mataná le-hud se otorgaba con la finalidad de remarcar el honor de la novia, y no como una transacción real.

Tras el fallecimiento del marido, la viuda tendría derecho a permanecer en el domicilio familiar y a recibir manutención durante tres meses, si no recogiera la ketubá (dote y principal). Una vez expirara el plazo, los herederos/descendientes o sus tutores podrían obligarle a abandonar el domicilio y le entregarían sus bienes, siempre y cuando el marido no hubiera dispuesto lo contrario por escrito ${ }^{62}$.

58 Tacanot de Argel (1394), núm. 3.

59 Tacanot de Argel (1394), núm. 4.

60 Tacanot de Argel (1394), núm. 5.

61 Tacanot de Argel (1394), núm. 6.

62 Tacanot de Argel (1394), núm. 7. Esta medida se empleaba principalmente para proteger la herencia de los herederos/descendientes, y evitar tener que cubrir de su parte los costes del mantenimiento de la viuda.

SEFARAD, vol. 81:2, julio-diciembre 2021, págs. 303-331. ISSN: 0037-0894. https://doi.org/10.3989/sefarad.021-011 


\subsubsection{Condiciones particulares}

La promulgación de estas ordenanzas procuraba la existencia de una norma legal interna relativa al régimen matrimonial y a la devolución patrimonial que debería ser respetada y cumplida por cada uno de los miembros de la comunidad, así como por los individuos que se unieran a ella. Al existir una reglamentación específica para cada etapa del matrimonio (casamiento, divorcio y fallecimiento de los cónyuges), la comisión encargada de elaborar estas ordenanzas prohibía que los desacuerdos surgidos entre una pareja fueran litigados ante tribunales no judíos (en el contexto magrebí, ante cadíes o jueces musulmanes) ${ }^{63}$.

La vigencia de las ordenanzas se extendía por un período de 20 años, y no podrían ser modificadas a través de enmiendas, ni tampoco anuladas hasta que no hubiera transcurrido el plazo establecido ${ }^{64}$. Pese a esto, las autoridades daban la posibilidad a los futuros cónyuges de establecer condiciones (tenaim) al respecto antes de formalizar su compromiso (šidujín) ${ }^{65}$. Por último, la fuerza legal de las ordenanzas no tendría carácter retroactivo, tal y como también se añade posteriormente en las ordenanzas de Fez, por lo que no afectaría a los casamientos previos a su promulgación ${ }^{66}$.

\section{OrdenanZas PROMUlgadAS EN EL SIGLO XV}

\subsection{Las tacanot de Fez (1494 y 1496)}

Las primeras ordenanzas de Fez de 1494 y 1496 se conservan en vernáculo (aljamía hebraico-romance), a diferencia del resto de ordenanzas citadas. Una de las primeras investigaciones dedicadas a estas leyes fue publicada en Sefarad por el erudito tangerino Abraham I. Laredo $(1948)^{67}$. En su estudio, Laredo realiza una valoración amplia de las

63 Tacanot de Argel (1394), núm. 8.

${ }^{64}$ Tacanot de Argel (1394), núm. 9.

65 Tacanot de Argel (1394), núm. 10.

66 Tacanot de Argel (1394), núm. 11.

67 Abraham Laredo, «Las taqanot de los expulsados de Castilla en Marruecos y su régimen matrimonial y sucesorial», Sefarad 8 (1948) págs. 245-276. 
mismas, aunque se centra en las de 1494 y 1496, que traduce a partir de la edición impresa (Séfer ha-Tacanot) incluida en la obra Kérem Hémer de R. Abraham Ancawa ${ }^{68}$. El enfoque de Laredo abría una vía para el estudio de las prácticas matrimoniales y de transmisión desde el punto de vista jurídico, pero también a través de documentación histórica relacionada con las comunidades judías medievales. Años después, en un artículo dedicado a la mujer sefardí, la hebraísta Yolanda Moreno Koch también manifestaba su interés por tales normas, ofreciendo un análisis de las mismas, en donde aportaba la transcripción de la ordenanza decimocuarta, que Laredo no había incluido ${ }^{69}$.

Las tacanot de 1494 contienen catorce cláusulas y un párrafo de cierre y fueron aprobadas el sábado 12 de siván de 5254 (17 de mayo de 1494), tras la festividad de Šabu'ot. Los firmantes en ellas, que actuaron en calidad de representantes de la comunidad, fueron Mošé Albaraneș, Mošé Mamón (Maymón), Yishaq Șeruyá y Binyamín b. R. Yosef Gabay. Estas primeras leyes, a las que se añadieron cuatro nuevas disposiciones validadas por los escribas o soferim Mošé Balansí y Yacob Paronte (sic, por Parente), fueron confirmadas en 1496.

\subsubsection{Práctica matrimonial}

La inestabilidad a la que se enfrentaron los judíos llegados a Fez queda patente en las tacanot: de hecho, en una de ellas se narra que, a causa de las grandes «tragedias pasadas», muchos de los judíos que

${ }^{68}$ Abraham Ancawa, Séfer Kérem Hémer (Livorno: 1871). Nacido en Salé (ca. 1810) en el seno de una familia sefardí, Ancawa realizó la primera edición impresa de las ordenanzas de Fez promulgadas entre 1494 y 1750; vid. Haim Zafran, Les juifs du Maroc. Vie sociale, économique et religieuse. Études de Taqanot et Responsa (Paris: Geuthner, 1972) pág. 27. Una edición y estudio de las ordenanzas en hebreo a partir de este texto se contiene en Shalom BAR-AsHer, The Taqanot of the Jews of Morocco: A Collection of Communal Ordinances from the $16^{\text {th }}$ to $18^{\text {th }}$ Century as found in Kerem Hemer II by Avraham Ankawa [heb.] (Jerusalem: Zalman Shazar, 1977), y Spanish and Portuguese Jews in Morocco (1492-1753). Sefer haTaqanot. The Book of Communal Ordinances [heb.] (Jerusalem: Akademon, 1990).

69 Yolanda Moreno Koch, «La mujer sefardí en Marruecos después de la expulsión de 1492», en Movimientos migratorios y expulsiones en la diáspora occidental. Terceros encuentros judaicos de Tudela (14-17 de julio de 1998), ed. Fermín Miranda García (Pamplona: Universidad Pública de Navarra, 2000) págs. 101-107. 
habían llegado convivían con sus mujeres sin que estas tuvieran una ketubá. Esta circunstancia no estaba permitida, puesto que este contrato era requisito indispensable para la formalización de un matrimonio, además de ser el instrumento que garantizaba los derechos y obligaciones de los cónyuges. Por este motivo, en la ordenanza duodécima (1494) se estipula que todos los miembros de la comunidad estarían obligados a escribir su ketubá sobre un pergamino nuevo antes del casamiento.

En cuanto a la composición de la ketubá, tal y como se había hecho en Argel un siglo antes, se establece que el novio debería realizar el pago del móhar, fijado en 200 zuzim para los matrimonios con mujeres vírgenes y en 100 zuzim para los matrimonios con viudas y divorciadas ${ }^{70}$. En el documento también constarían las aportaciones hechas por los cónyuges: en el caso del novio, las arras y las donaciones adicionales (matanot), y en el de la novia, la dote. El valor de la ketubá debería ser superior a 20 onzas de plata, aunque los contrayentes optaran por entregarlas por medio de donaciones. Esta norma también se debería aplicar en el caso de los matrimonios que no hubieran elaborado su ketubá o en aquellos que surgiera alguna disputa entre los cónyuges o los herederos y no apareciera la ketubá ${ }^{71}$.

En relación a la ceremonia nupcial (nisuín), el novio y los testigos presentes deberían firmar la ketubá ante un minián. La presencia de diez varones judíos tendría por fin asegurar la validez de la unión y conferir al matrimonio un carácter oficial y público, como se especifica en las ordenanzas generales de Valladolid $(1432)^{72}$. Según la primera tacaná de 1494, el minián debería estar compuesto por, al menos, un sabio o un juez, que sería el encargado de legalizar y bendecir la unión ${ }^{73}$.

\subsubsection{Condiciones particulares}

Los dirigentes de la comunidad especificaron que en las ketubot se podrían establecer tenaim o condiciones acordadas por los contrayentes a fin

70 Tacanot de Fez (1496), núm. 1.

71 Tacanot de Fez (1496), núm. 2

72 Tacanot de Valladolid (1432), cap. 3, fol. 11.

73 Tacanot de Fez (1494), núm. 1. 
de que el compromiso quedara regulado según sus intereses. Las modificaciones realizadas sobre el régimen contenido en las ordenanzas deberían precisarse en el contrato para que adquirieran valor legal ${ }^{74}$. Por lo tanto, la cantidad establecida para el compromiso matrimonial podría ser distribuida en donaciones, con la condición de que quedara reflejada en el documento ${ }^{75}$.

\subsubsection{Ruptura del matrimonio}

Aunque no hay ninguna tacaná en las ordenanzas en la que se legislen cuestiones concernientes a la disolución de esponsales, la ordenanza decimocuarta (1494) se centra en la concesión del divorcio a la mujer en previsión de muerte, una medida que ya aparece recogida en las $t a-$ canot de Toledo (s. XIII). La comunidad de expulsados instaba a todo hombre enfermo o en peligro a entregar el guet a su mujer para eximirla del levirato ${ }^{76}$. El propósito de esta tacaná era facilitar la disolución del matrimonio tras el fallecimiento del marido sin depender de la concesión de la halișá, ceremonia en la que el hermano del fallecido o levir liberaba a la viuda de mantener el compromiso matrimonial. Además, en la ordenanza se especifica que la mujer que obtuviera el divorcio a causa de este motivo, sería tratada jurídicamente como viuda tras el fallecimiento de su marido. De esta manera, tendría derecho a recuperar los bienes de la ketubá o a recibir su porción de la herencia.

\subsubsection{Modelo de devolución}

Las ordenanzas establecen un modelo de devolución del patrimonio según hubiera, o no, hijos. Por lo tanto, se excluye el modelo de devolución de los bienes de la ketubá ${ }^{77}$. En primer lugar, se ordena que cuando

74 Tacanot de Fez (1494), núm. 13 y (1496), núm. 1.

75 Tacanot de Fez (1496), núm. 3.

76 Tacanot de Fez (1494), núm. 14.

77 LaRedo ( «Las taqanot de los expulsados de Castilla en Marruecos y su régimen matrimonial y sucesorial», pág. 259) ya apuntó que en estas ordenanzas se establece un modelo propio de un régimen de bienes comunes, en el que los cónyuges transmiten la totalidad de su patrimonio al cónyuge superviviente y a y sus herederos/descendientes. 
uno de los cónyuges falleciera ab intestato, ese mismo día, un sabio, un juez o un sofer debería proceder al inventario de todos los bienes existentes, que formarían parte del fondo común. Con el dinero del fondo se debería comprar lo necesario para el enterramiento del fallecido ${ }^{78}$.

El modelo de devolución establecido debería respetarse incluso si se quisiera hacer una donación inter-vivos o dictar las últimas voluntades ${ }^{79}$. El reparto de los bienes de la persona fallecida se llevaría a cabo durante los siete primeros días del abelut o período de doce meses de luto que seguía, en particular, al fallecimiento del padre o la madre ${ }^{80}$.

Si la mujer falleciera sin descendientes y no tuviera padre, ni hermanos varones, el marido heredaría dos tercios de los bienes y los herederos el tercio restante. Al referirse a los herederos, las tacanot especifican que se trata de parientes de hasta tercer grado, es decir hasta los primos segundos, siempre y cuando vivieran en el reino de Fez. En otras leyes, como las de Tudela, se especifica que el viudo tendría derecho a recibir la mitad de la herencia, una porción ligeramente inferior a la establecida en Fez.

Respecto al fallecimiento del marido, antes de proceder a la distribución de la herencia se debería hacer entrega a la viuda, ante un juez judío o dayyán, de un ajuar para el período de duelo valorado en «un par de camisas e una saya» nuevas ${ }^{81}$. Si el matrimonio no hubiera concebido descendencia y el padre y hermanos del fallecido estuvieran ausentes, la viuda debería tomar dos tercios de la herencia y los herederos de hasta tercer grado el tercio restante. En las ordenanzas de Toledo, Molina y Argel no se contempló la posibilidad de que la mujer tomara parte de la herencia del marido si no hubiera descendientes. Sin embargo, en las leyes de Tudela se observa que, si la viuda renunciara a su ketubá, podría recibir la mitad de la herencia y los herederos se quedarían con la otra porción.

$\mathrm{Si}$, por el contrario, uno de los cónyuges falleciera dejando descendencia, o si su padre o hermanos varones vivieran y residieran en Fez, el

78 Tacanot de Fez (1494), núm. 6.

79 Donaciones inter-vivos y últimas voluntades se deberían redactar en presencia de un sabio o un juez para que fuesen válidas; vid. Tacanot de Fez (1494), núm. 11.

80 Tacanot de Fez (1494), núm. 9.

81 Tacanot de Fez (1494), núm. 7. 
cónyuge superviviente dividiría la herencia en dos mitades con el padre, o los hermanos varones, o aquellos hijos e hijas casaderas que tuvieran más de treinta días de edad ${ }^{82}$. Al considerar al padre y a los hermanos descendientes, la familia del fallecido podría recuperar la mitad de la herencia en caso de que no hubiera hijos. Si en el momento del fallecimiento del marido la viuda estuviera embarazada o tuviera un bebé lactante, los gastos ocasionados por el mantenimiento de la criatura deberían correr a cuenta del dinero de la herencia, y no del suyo propio. Sin embargo, estaría obligada a dar de mamar a la criatura durante veinticuatro meses ${ }^{83}$.

En cuanto a la distribución de la herencia entre los descendientes, tanto si falleciera el padre, como la madre, la parte de la herencia destinada a las hijas, entiéndase las que no estuvieran casadas, debería emplearse para su dote. Además, estas jóvenes casaderas (arusot) también tendrían derecho a heredar de sus padres si, tras su dotación, hubiera sobrado dinero $\mathrm{u}$ otros bienes restantes ${ }^{84}$.

\subsubsection{Pago de deudas}

Si las deudas las dejara la mujer, estas deberían pagarse del «montón» de la herencia antes de su reparto; de la misma manera se legisló en las ordenanzas de Toledo ${ }^{85}$. Por otro lado, si los débitos fueran del marido, se deberían amortizar con la parte de la herencia correspondiente a los herederos, en caso de que no hubiera descendientes o su padre y hermanos varones no vivieran. Si, por el contrario, el fallecido hubiera tenido hijos de sus respectivos matrimonios, las deudas se pagarían con los bienes del fondo común o «montón» ${ }^{86}$. Por último, si el marido hubiera dado prendas

82 En el caso de que el marido falleciera, la herencia sería repartida entre todos sus hijos, aunque fueran de diferentes matrimonios.

83 Tacanot de Fez (1494), núm. 10.

84 Tacanot de Fez (1494), núm. 8. Esta disposición también se observa en las ordenanzas de Toledo y Tudela, y debió de ser común entre las comunidades hispánicas, puesto que, a más dote, mayores eran las posibilidades de acordar un buen casamiento.

85 Llamas, «Documentos para la historia jurídica de las aljamas hebreas de Toledo y Molina», pág. 266.

86 Tacanot de Fez (1494), núm. 4. 
en señal de pago de sus deudas, tales bienes deberían servir para amortizarlas y tras esto se procedería al reparto de la herencia.

\section{Consideraciones finales}

En el período pleno y bajomedieval, las aljamas hispano-judías tenían capacidad jurídica para emitir sus propias leyes en relación con las prácticas matrimoniales y la devolución de la herencia. Desde el siglo XIII se constata la promulgación de normas comunitarias de carácter local que perseguían una homogeneización legal a este respecto. Estas leyes tenían una duración limitada y no solían ser aplicadas con carácter retroactivo. No obstante, la legalidad de los acuerdos alcanzados por las familias de los futuros cónyuges, o por estos mismos, era superior a la de las tacanot. En ausencia de una normativa comunitaria, los judíos solían guiarse por la costumbre imperante, que variaba en función del lugar. En esta ocasión, se han estudiado ordenanzas procedentes de las coronas de Castilla y Aragón y del reino de Navarra. Sin embargo, no todos los territorios están representados, y cabe expresar la ausencia de información para las zonas de Cataluña y sur de Castilla.

Del estudio de las ordenanzas se concluye la existencia de dos modelos de devolución patrimonial: el primero se basaba en los bienes aportados en la ketubá; el segundo regía la transmisión de la herencia de un individuo que hubiera estado desposado. Por lo general, las comunidades emisoras prefirieron regular la devolución de los bienes matrimoniales en contraposición a la de la herencia, asumiendo la prevalencia del régimen de capitulación o separación de bienes.

En lo que se refiere a la distribución de los bienes de la ketubá, el marido resultaría receptor de una porción de los bienes de la mujer en todos los casos, ya fuera mayor o menor. En cambio, a ella solo se le restituirían unos bienes que, por derecho propio, ya le correspondían. En consecuencia, la restitución no debe ser considerada herencia. Es más, si la viuda optara por recibir una porción de la herencia de su difunto marido, estaría renunciando a los bienes de la ketubá, cuya cantidad podría ser superior a la que fuera a recibir.

Los herederos, en particular el padre del cónyuge fallecido, tendrían preferencia en la distribución de la herencia de una persona sin hijos. 
Sin embargo, ante la presencia de los últimos, los herederos quedarían excluidos de la herencia del fallecido. Los descendientes heredarían de sus progenitores a partes iguales, a excepción de las doncellas, que recibirían de la herencia de sus padres su dote, y las hijas desposadas, que quedarían excluidas de la devolución en la mayoría de los casos.

Las ordenanzas estudiadas revelan similitudes y diferencias entre los modelos. En relación al fallecimiento sin descendencia, el primer modelo establece que, ante el fallecimiento de la mujer, lo común sería que la dote fuera distribuida entre el viudo y la familia de esta. Por lo tanto, el marido no tendría que hacer entrega de las arras en ningún caso (Toledo, Molina, Soria, Palma de Mallorca y Argel). Si, por el contrario, el marido muriera, todas las ordenanzas coinciden en la restitución de la dote y en un aporte que oscila entre la mitad y un cuarto de la dote (Toledo, Molina, Soria, Palma de Mallorca y Argel). Los herederos quedarían como propietarios de las arras y la herencia del marido. En lo que se refiere al segundo modelo, en el caso de las ordenanzas de Tudela se establece que el cónyuge superviviente y los herederos podrían compartir la herencia en dos mitades. En las leyes de Fez se le concede una porción ligeramente superior al cónyuge superviviente, que recibiría un tercio de los bienes del fallecido.

En matrimonio con hijos, se aplicaría una devolución de bienes basada en el segundo modelo. De esta manera, el cónyuge superviviente y los descendientes se repartirían la herencia en dos mitades (Toledo, Molina, Soria, Tudela y Fez). No obstante, si fuera el marido el que falleciera, en las ordenanzas de Toledo, Molina y Tudela se da la posibilidad a los hijos de escoger entre devolver la dote y las arras a su madre o hacerla partícipe de la herencia. A este respecto, las ordenanzas de Palma de Mallorca y Argel, que comparten una misma tradición legal, no contemplan el uso de ninguno de los modelos en caso de que el fallecido fuera el marido. Tan solo se regula la distribución de la ketubá entre el marido y los descendientes, otorgando al primero el derecho a quedarse con la herencia de la fallecida.

Recibido: $15 / 10 / 2021$

Aceptado: 06/11/2021 
